\title{
Toyota's Slow Response to Manufacturing Defects Leading to Recalls: Result of Poor Communication Strategy
}

\author{
Oyinkepreye L. Bebeteidoh ${ }^{1}$, Stephen A. Takim ${ }^{2}$ \\ ${ }^{1}$ Department of Marine and Mechanical Engineering, Niger Delta University, Wilberforce Island, Nigeria \\ ${ }^{2}$ Mechanical Engineering Department, Cross River University of Technology, Calabar, Nigeria \\ Email: ^engrpreye@mail.ndu.edu.ng
}

How to cite this paper: Bebeteidoh, O.L. and Takim, S.A. (2016) Toyota's Slow Response to Manufacturing Defects Leading to Recalls: Result of Poor Communication Strategy. Journal of Transportation Technologies, 6, 420-435.

http://dx.doi.org/10.4236/jtts.2016.65034

Received: March 8, 2016

Accepted: October 14, 2016

Published: October 17, 2016

Copyright $\odot 2016$ by authors and Scientific Research Publishing Inc. This work is licensed under the Creative Commons Attribution International License (CC BY 4.0).

http://creativecommons.org/licenses/by/4.0/

\begin{abstract}
The recall of vehicles in the automobile industry is not limited to any particular company. Recalls most often have been attributed to defective parts supplied by tier one and tier two suppliers. Toyota, a world leader in the manufacture of automobiles, built on world class corporate brand and Principles known as the Toyota Way, and located in about 53 countries in the world, with most of its production taking place in the North America and Japan. Its Communication strategy leading to recalls has brought it into conflict with its customers and regulatory agencies. Toyota's seeming departure from its core principles in the Toyota Way has also brought it into conflict with suppliers and affected its production. Answers will be sought for the following research questions: 1) Why with its Toyota Way, Communication became a challenge for Toyota? 2) What is the role of the Media, in Toyota's issues of recall? A detailed literature survey was conducted for Toyota's communication strategy. A dialectic inquiry was used to analyse the acquired data, from interviews conducted.
\end{abstract}

\section{Keywords}

Communication, Defects, Manufacturing, Media, Strategy, Toyota Way

\section{Introduction}

The automobile industry has been plagued by recalls in recent times attributed to one sort of defect to another [1]. According to [2], automotive recalls are issued by manufacturers to inform customers the presence of a defect in their car, bus or truck that may lead to property damage or injury. Table 1 shows a list of recalls from 2011-2013 by top manufacturers, while Figure 1 shows in details the recalls made by top vehicle 
manufacturers running from 2011 through 2013.

According to [3], Toyota recalled 6.5 million cars in 2015 as a result of defective window switches.

\subsection{Strategy}

Strategy is defined as a representation of the path an organization is taking, what the organization intends to do and how it also wants to get it done [4]. According to [1] strategy is a cleverly essential action directed by a handful of modest guidelines that are outstanding and different. The strategy a company adopts helps give direction to its growth pattern [5]. Averred that strategy is not goals, neither is strategy purpose or objectives, but strategy describes how those thing will be achieved.

\subsection{Crisis Communication Strategy}

"I've visited Toyota's website-particularly the page where the company displayed the news it wanted the world to see-at least once a day over the past week. I'm sorry to say the site was a study in mediocrity. There's presentation without invitation and information without engagement. If the site were a car, it would be a 1982 Toyota Corollareliable, slightly uncomfortable, and an awkward anachronism"... [6].

One of the basic reasons for Toyota's successes is the "Toyota Way", which lays emphasis on response to people and continuous improvement [7]. One of the lessons learnt at Toyota is that safety and peace of mind are two separate things. I will voice it out categorically that Toyota's vehicles are very safe, but we could have done better in explaining to our customers, so that they could have rest of mind [8]. Toyota's inability to

Table 1. Recalls issued by top manufacturers in 2011-2013 [2].

\begin{tabular}{ccc}
\hline Company & Year & Vehicles Recalled in Million \\
\hline Toyota & 2011 & 3.5 \\
Ford & 2011 & 2.7 \\
Honda & 2011 & 1.5 \\
\hline Toyota & 2012 & 5.3 \\
Honda & 2012 & 3.6 \\
GM & 2012 & 1.5 \\
Ford & 2012 & 1.4 \\
Chrysler & 2012 & 1.3 \\
\hline Toyota & 2013 & 5.3 \\
Chrysler & 2013 & 4.7 \\
Honda & 2013 & 2.8 \\
Hyundai & 2013 & 2.2 \\
Ford & 2013 & 1.2 \\
\hline
\end{tabular}




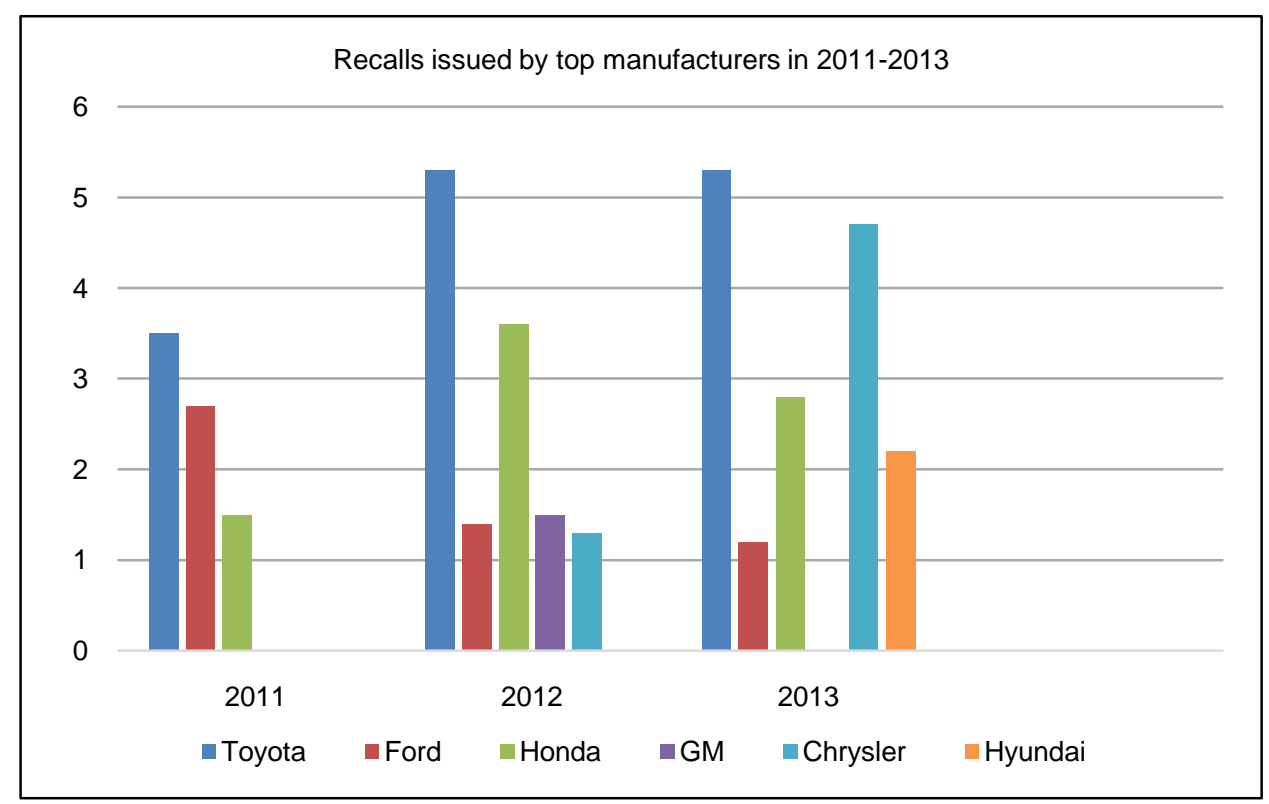

Figure 1. Recalls by top vehicle manufacturers in 2011-2013.

explain to its customers on issues of "defects" did not spell well for the company, at the time it had the issues of recall.

The way Toyota handled the recall crisis due to manufacturing defects had caused uproar both in Japan and the United State of America. In response to the outcry to its poor handling of the crisis, Toyota set up a business reform department, with the sole aim of handling its poor internal and external communication system. With Toyota ignoring early warning signs, it may suggest that decision makers in Toyota would have been liable for the delay in responding at the early periods of the crisis [7]. According to [6], while describing how Toyota handled the recall issues, described it as a tragedy, self inflicted. The researcher holds Toyota responsible for the failures in test and design which led to hazardously dangerous vehicles on the road. The researcher further described how Toyota uses several media houses to promote its new vehicles like, Lexus, Prius and Scion products, while refusing to do same at the critical time of recalls, describing it as an operational and strategic failure. Toyota and its customers deserve better.

In a research carried out by [9], it averred that Toyota's public relations know-how does not measure up with its whole strength as a global manufacturer. While noting that with Toyota's slippages, they still continue to win top ranking in quality surveys. In a recent research conducted by [7] and [9] explained that Toyota's response to the issue of floor mats leading to the San Diego crash was disastrous. The refusal of Toyota to issue a consumer warning about its all weather floor mats, even after NHTSA had concluded their analysis. Even with Toyota's late intervention, it instructed its dealers to only inspect floor mats brought in by its numerous customers, rather than issuing a customer safety warning [10] in their research grouped Toyota's recall crisis into four stages, the Preliminary crisis stage, the Acute crisis stage, the chronic crisis stage and 
the crisis resolution stage, as shown in Figure 2.

- Preliminary Crisis Stage-This stage can best be described as the stage of warning that may likely be very petite or abrupt. In Toyota case the stage pre-crisis was not clear to company executives, so officials could not take the appropriate steps to correct issues in the later part of 2007. In certain circumstances, a pre-crisis alertness could be much skewed in addition to being very hard to identify. In most cases this period is obvious, but action is not taken, which leads to an acute crisis, which was the case with Toyota. The researcher described Toyota's lack of response as a result of a pre-crisis - a dearth of rejoinder that may have been caused by "analysis paralysis" or compulsive decision making within the company. The researcher while describing the importance of pre-crisis, say it is easier for companies to manage crisis at this stage.

- Acute Crisis Stage-Toyota's inability to respond to the crisis at the preliminary or warning stage brought it to the acute stage. The ability to recognize and manage the warning stage, before it gets to the acute stage, is what differentiates a firm that needlessly suffers during a crisis, and that which benefits from the crisis. Corporate Leaders at Toyota have to understand that the pre-crisis stage leads to the acute stage, and when crisis get to this point it may be a point of no return. At this point Toyota had to recognize that some damage had been done to their corporate image; the tendency for more damage to occur depends on the, ingenuity and quality of the corporate leadership. Toyota's management team failed to efficiently handle the acute crisis stage, and dispel the huge negative outcomes that this stage brought into focus.

- Chronic Crisis Stage-At the point of the chronic crisis stage, it is expected that the crisis would have been brought under control, but for the lack of attention at the time of the pre-crisis, and the negative events that transpired throughout the stage

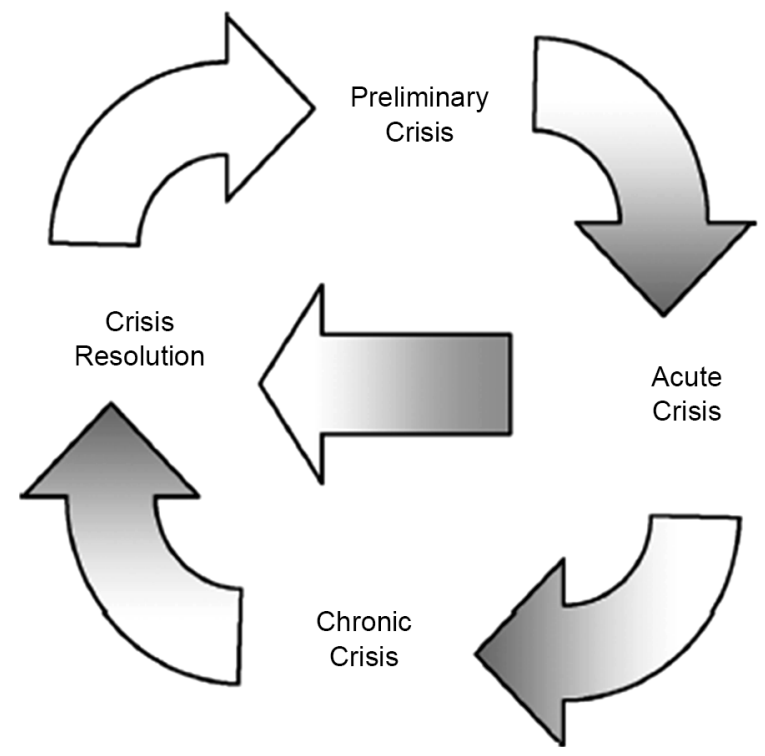

Figure 2. Typical crisis cycle phases [10]. 
of acute crisis will make this stage continue and consume more resources-principally in Toyota's effort to restore its missing customer confidence in the company and its goods. The operational balance of its leaders may have been lost and fallen victim to arrogance due to their huge success and power. Toyota joined the list of companies faced with unpredictable corporate crisis in the first decade of the $21^{\text {st }}$ century.

- Crisis Resolution Stage-This is the fourth stage of the crisis cycle as shown in Figure 3, it ought to be the goal of the manager's, all through the previous three phases. Once issues are at the pre-crisis stage, company administrator's objective as an efficient crisis manager is to take absolute charge quickly and determine which would be the most appropriate channel to reaching a resolution to the crisis. The approach taken by the Toyota leadership has shown that denial to reduce and mollify the precarious safety situation it was faced with was the wrong approach. Company leaders failed to face the public for weeks, and appeared to be less concerned about critical safety issues, thereby risking the trust of its numerous customers and dealers worldwide.

According to [11] a company's reputation is widely regarded as its greatest asset. Unpredictable events or crisis can bring a company's activities to disrepute. A company's unrestrained response to crisis situations can serve to reduce and even repair its damaged reputation.

In any case the several stages of crisis responsibility is a crucial sign of the budding reputational impairment a crisis might mete out on a company [11]. In the heat of the crisis, Toyota continued its insistence that there were no defects, and the reason for the uncontrolled acceleration was as a result of the vehicles floor mats. Toyota went further to send its teeming customers at the end of October 2009 stating explicitly that "no defect exists". The first concern of a company at the time of crisis is to defend its stakeholders from harm, not to protect its own name. It can do this through adapting information and instructing information [11].

\section{Methodology}

The research method used in carrying out this research is qualitative in nature, making

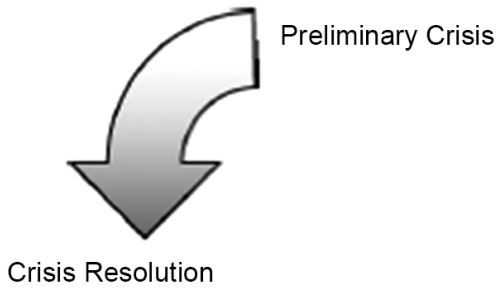

Acute Crisis

Figure 3. A preferred crisis cycle appearance [10]. 
use of primary and secondary data. Primary data's were gotten from interviews conducted, and secondary data's were gotten from journal publications, books, video's and transcripts. According to [12] qualitative research method are methods that sheds light on "how" and "why" questions, and are good in capturing process and pay more attention to why certain firms benefit from an intervention and others do not benefit. Interviews in research can either be structured, semi-structured and unstructured.

\subsection{The Dialectic Inquiry}

The dialectic inquiry (DI) is a qualitative research method which is well structured for the study of organizational sense making, as being understood by participants.

According to [13] dialectical inquiry should not just be described as a way in which knowledge is generated: it is a major part of social work practice which continually sheds light on the oppression which has arisen from contradictions within the capitalist economy.

\subsection{Interview}

The researcher carried out interviews as a part of the data collection technique for this research project. A semi-structured interview was used for the collection of primary data for the purpose of this research project. The researcher interviewed an academic Professor of Business Strategy and Economics from one of the United Kingdom's top universities who featured prominently in the British Broadcasting Corporation (BBC 2) Video "The Recall” [14], the head of one of United Kingdom's vehicle regulatory agencies and an industry expert. All interviews were done between May through July of 2013.

Secondary data was also collected by the following techniques:

- Government Data-The transcripts used by the researcher for the analysis are government data's, and are very rich and accurate.

- The Internet-The researcher also made use of internet sources, for his data collection. Powerful search engines like Google, Google Scholars and EBSCO Host, where also helpful in this process.

- Scholarly Journals-This form of journals contains reports of original research done by experts, which has also been peer reviewed, accurate and relevant to the research.

- Published Data-Reference Books, Websites and Technical reports.

\section{Semi-Structured Interview}

The semi-structured interviews are usually non-standardized and a mostly used in qualitative analysis, the researcher in this case does not test for any hypothesis. The researcher has a list of important questions, issues and key themes to be addressed in the interview. The interviewer controls the order, at which the questions are asked, and additional questions may be asked and some may not have been in the original list of questions [1]. In the semi-structured interview the researcher does not need to follow a predesigned interview guide. 


\subsection{Research Survey}

The response to the interviews was obtained from government regulatory agencies, industry expert and a Professor of Strategy and Economics who is knowledgeable about Toyota. The government agency was in the best position to ascertain the adherence of automobile manufacturers to quality standards. The industry expert was able to explain the issues of suppliers and auto manufacturers, while the Professor who featured prominently in the BBC 2 video "The Recall" was able to answer some few questions about Toyota's strategy of growth. This would assist the researcher in drawing a good analysis, discussion and recommendation to addressing the issues of "defects".

In conducting the research, the researcher was expected to abide to certain norms upon which viability and originality of the research is based [1], these norms were observed by the researchers, wherein the anonymity clause was triggered by all three interviewees.

\section{The Role of the Media}

The news media and other internet publishers are basically a major threat to the reputation of any organization, with the public's sensitive nature to organizational scandal [15]. According to [16] frames are potent means which can help describe and resolve glitches and also shape public view. Public view of and deductions with respect to events is reliant on what feature or information is salient. The theory of framing implies that the mass media do more to create saliency, by selecting what they will include and what they will exclude from a story; in which case the news media regulates or outlines the story meaning, thereby shaping people's opinion of the story.

The leadership position of Toyota in quality has not been compromised except in the news media. Looking at the under listed independent survey data's from J.D Powers and Consumer safety for 2009, shows how Toyota's quality and reliability is still the best in the Auto industry [8]:

- J.D Powers initial quality survey of 2009 placed Toyota first place in 10 out of 19 categories, compared to any other vehicle manufacturer.

- In the same year 2009, J.D Powers dependability study for 2009, Toyota placed first in 8 out of 19 categories compared to any other automobile manufacturer.

- Consumer report for 2009, Toyota brands took three out of the top five slots.

None of the above rankings shows Toyota's quality as going down [8]. The quality standing of Toyota, had started showing signs of fraying, before the recent recalls, Consumer Reports 2008, showed that three of Toyota's models were being dropped from its recommended list, whereas Honda Motors tested vehicles made the Consumer Reports recommended list at $100 \%$, while Toyota Motors percentage fell to $73 \%$, down from $85 \%$ the previous year [17].

According to [18] the media had not been forte coming with the truth, describing a report from The Economist, the researcher explained how the paper handled the facts about the recalls, describing how Toyota's recall issues indicates a bad quality malaise of how Toyota decided to grow the brand, and how this has led to problems in its sup- 
ply-chain management. With this same assertion made by other media houses, there is a grave danger that it will become the accepted norm. In their research, [19] averred that the responses from Toyota to customer complaints were seen to be very insufficient, and started to put a strain on public trust, regulators, car buyers and officials of government.

\section{Conclusion}

\subsection{Research Question One}

Toyota's response to consumer complaints was poor. According to [1], in the heat of the crisis, Toyota continued its insistence that there were no defects, and the reason for the uncontrolled acceleration was as a result of the vehicle floor mats. Toyota went further to send its teeming customers at the end of October 2009 stating explicitly that "no defect exists". With the NHTSA responding to Toyota's letter to its customers, it was called "misleading" and "inaccurate". The rebuke on Toyota by the Feds turned what was a big story to an even bigger one. According to [11], the major concern of any organization facing crisis is to shield its stakeholders from harm, not to protect its own name; and this can be done by instructing information and adapting information.

It's method of handling reporting issues according to [20] whereby company executives in the U.S. had to report to Japan before decisions were taken about recalls was also poor. Its initial denial of manufacturing defects in its cars, and later acceptance, do not tell well for a supposed leader in the automotive industry.

Early warning signs were also neglected by Toyota.

\subsection{Research Question Two}

While it is known that the media play a great role in information dissemination, Toyota was not able to relate properly with the media [20]. Avers that Toyota's problems are due to political pressure, but according to the print and electronic media, the crisis lies in Toyota's extreme drive for growth and cost cutting measures. [19] posited on the relationship between the media and public opinion and further added that Toyota's inability to set the agenda by coming out promptly to address the media on issues of defects leading to recalls, led the media to set the agenda on issues of defects leading to recalls, attributed to Toyota.

\section{Recommendation}

Although the researcher acknowledges the fact that Toyota has made certain changes in tune with the issue of communication; the organization still has to do more in the North America. Since North America is a major market for Toyota and also host its highest number of plants outside Japan, the need for Toyota Japan to give those in the U.S. some leverage to operate cannot be over emphasised. Also Toyota should be more open and ready to listen to its customer complaints, by responding as quickly as possible.

The top management of Toyota Japan should involve in leadership other than in 
management, for the reason that while management deals with the intricacies of budgeting and planning [21] leadership is more of transformation, while looking at the vision and direction of the organization [22].

The leadership of Toyota should now be aware that the organization is now a global one and no longer a Japanese company, and should endeavour to allow for easy communication flow between Toyota Japan and its production plants the world over.

\section{References}

[1] Lucky, B. and Takim, S. (2015) Manufacturing Defects in the Automobile Industry, a Case Study of the Remote Causes and Effects of Toyota's Transmission Malfunctions in Cars. IJEAS, 2, 15-28.

[2] Klyatis, L. (2015) Introduction to Successful Predicting of Product Performance (Reliability, Durability, Safety, Quality, Recalls, Profit, Life Cycle Cost, and Others). SAE Technical Paper, No. 2015-01-0487. http://dx.doi.org/10.4271/2015-01-0487

[3] McHugh, J. (2015) Toyota Recall 2015: Is Your Car Affected? How to Check Models, Year to See If You're One of 6.5M Affected. International Business Times. http://www.ibtimes.com/toyota-recall-2015-your-car-affected-how-check-model-year-see-i f-youre-one-65m-2150068

[4] Hill, T. (2005) Operations Management. 2nd Edition, Palgrave Macmillan, New York.

[5] Pettigrew, A.M., Thomas, H. and Whittington, R., Eds. (2001) Handbook of Strategy and Management. Sage, London.

[6] Schrage, M. (2010) The Toyota Brand: Struggling Online and Off. Harvard Business Review. http://blogs.hbr.org/schrage/2010/02/the-toyota-brand-struggling-on.html

[7] Andrews, P.A., Simon, J., Tian, F. and Zhao, J. (2011) The Toyota Crisis: An Economic, Operational and Strategic Analysis of Massive Recall. Management Research Review, 34, 1064-1077. http://dx.doi.org/10.1108/01409171111171474

[8] Liker, J. and Ogden, T.N. (2011) Toyota Under Fire; How Toyota Faced the Challenges of the Recall and the Recession to Come Out Stronger. McGraw-Hill, New York.

[9] Wharton (2010) Quality on the Line: The Fallout from Toyota's Recall. http://knowledge.wharton.upenn.edu/article/quality-on-the-line-the-fallout-from-toyotas-r ecall/

[10] Heller, V.L. and Darling, J.R. (2012) Anatomy of Crisis Management: Lessons from the Infamous Toyota Case. European Business Review, 24, 151-168. http://dx.doi.org/10.1108/09555341211204017

[11] Coombs, W.T. (2007) Protecting Organizational Reputations during a Crisis: The Development and Application of Situational Crisis Communication Theory. Corporate Reputation Review, 10, 163-176. http://dx.doi.org/10.1057/palgrave.crr.1550049

[12] Prowse, M. and Camfield, L. (2013) Improving the Quality of Development Assistance: What Role for Qualitative Methods in Randomized Experiments? Progress in Development Studies, 13, 51-61. http://dx.doi.org/10.1177/146499341201300104

[13] Dybicz, P. and Pyles, L. (2011) 'The Dialectic Method: A Critical and Postmodern Alternative to the Scientific Method. Advances in Social Work, 12, 301-317.

[14] BBC 2 (2010) Total Recall: The Toyota Story. Media Services Lancaster Library, Coventry University.

[15] Tucker, L. and Melewar, T.C. (2005) Corporate Reputation and Crisis Management: The 
Threat and Manageability of Anti-Corporatism. Corporate Reputation Review, 7, 377-387. http://dx.doi.org/10.1057/palgrave.crr.1540233

[16] An, S. and Gower, K.K. (2009) How Do the News Media Frame Crisis? A Content Analysis of Crisis News Coverage. Public Relations Review, 35, 107-112.

http://dx.doi.org/10.1016/j.pubrev.2009.01.010

[17] Cole, E.R (2010) Toyota's Hyper Growth and Complexity Trap. Harvard Business Review. http://blogs.hbr.org/cs/2010/02/toyota_the_downside_of_hyper_g.html

[18] Liker, J.K (2010) The Wrong Lessons from Toyota's Recalls- And the Truth. Harvard Business Review. http://blogs.hbr.org/research/2010/03/does-media-coverage-of-toyota.html

[19] Fan, D., Geddes, D. and Flory, F. (2013) The Toyota Recall Crisis: Media Impact on Toyota's Corporate Brand Reputation. Corporate Reputation Review, 16, 99-117.

http://dx.doi.org/10.1057/crr.2013.6

[20] Cole, E.R. (2011) What Really Happened to Toyota? MIT Sloans Management Review, 52, 29-36.

[21] Andriopoulos, C. and Dawson, P. (2009) Managing Change, Creativity and Innovation. Sage Publications, New York.

[22] Raelin, J.A. (2012) Leadership in Participatory Organizational Change. Journal of Organizational Change Management, 25, 7-23. http://dx.doi.org/10.1108/09534811211199574

\section{Abbreviation}

DI Dialectic Inquiry

GM General Motors

JIT Just in Time Technique

NHTSA National Highway Traffic Safety Administration

TPS Toyota Production System 


\section{Appendix}

\section{Interview with a Staff of One of the Regulatory Agencies in United Kingdom}

The researcher introduces himself, the topic of the dissertation, and hands over the informed consent form and the participant information leaflet to the interviewee.

\section{Question 1}

Interviewer: How long have you been working in the automobile industry?

Interviewee: I joined Jaguar in 1976; I have been in the automobile sector for 37 years.

\section{Question 2}

Interviewer: What is the nature of your work?

Interviewee: I am the chief executive of one of the certification agencies in the UK. We are one of the type approval agencies.

\section{Question 3}

Interviewer: What kind of job does the certification agency do?

Interviewee: The certification agency approves new vehicle systems and components to European directives and United Nations regulations.

\section{Question 4}

Interviewer: Have you heard of the phrase automobile defects?

Interviewee: Yes.

\section{Question 5}

Interviewer: How can you describe defects in vehicles?

Interviewee: Defects can be described in a number of ways; quite simply a defect is any system or component that is not working as designed.

\section{Question 6}

Interviewer: What do you think brings about defects in the manufacturing of automobiles?

Interviewee: It could be many causes, it could be process deficiencies, it could be human deficiencies, it could be machinery malfunction, it could be the design specification is not just up to standard.

\section{Question 7}

Interviewer: Can automobile companies reduce the frequent causes of defects?

Interviewee: They can, they do (Calls researchers' name) modern vehicles now are very, very reliable, if you compare the main distance between failure now and say twenty years ago, it's significantly better. If you take a modern automotive passenger car engine, it is designed to work for over $300,000 \mathrm{~km}$ without any major rectification work. Twenty years ago that would have considerably less; it would have been say half, so modern automobiles and systems are very reliable. 


\section{Question 8}

Interviewer: The challenge the customers are facing is that the recalls have become frequent, this year alone there have been several recalls ranging from air bags (Interviewee interjects)... From Ford, to Toyota, to Nissan, the question the customers will be asking is, who certifies those defective parts, is it that the certification agencies don't certify, how do they certify them, and how do these defects still get out of the production floor?

Interviewee: The certification authority would certify that the system works to the adequate standards, what it doesn't do is to ensure reliability. The certification authority is not responsible for the reliability of the system. There is no discussion about reliability between the approving authority and the manufacturer. Now you say that there are more recalls these days... I don't know if there are more recalls these days, but what i do know that vehicles are far more complex, you would not have had airbags recall twenty years ago, because then cars did not have airbags. I will want to still add that vehicles these days are far more reliable than say twenty years ago.

\section{Question 9}

Interviewer: Does new features in car affect the quality?

Interviewee: Well it can do, because the vehicle system architecture is now more complex so you have so many new features, which are managed through complex control measures. One of the challenges for the manufacturer is to have the proper integration of all these different systems. Now a modern transport passenger car can have many features, and many of these have to speak to each other. These features are so complex that it won't be possible to test for all the failure modes, because now there are many failure modes. So there is a new now functional safety process, being developed called ISO26262, which is presently being developed to improve the vehicles functional safety reliability of its complex systems.

\section{Question 10}

Interviewer: In your own words how can you describe vehicle recalls?

Interviewee: ... Well how do I describe that? They can have many... ah different formats, now in the United Kingdom, VOSA is the authority for managing recalls, and VOSA really only gets involved if it is a safety recall. The reality is most vehicles are subject to recall and change, and the owner is not aware of that. Ok

So the vehicle manufacturer can be making improvements to the vehicle all the time, would be fixing the vehicle and making changes. So it is only when you have a major safety issue that you would have a safety campaign, whereby as in the United Kingdom the regulatory agency, in which case VOSA will then come in. If you look at the VOSA website, there will be a section that covers recall. Many cars are involved in recalls yearly. It is normal to the industry every year... so every time a vehicle is recalled there is a cost of rectification, and somebody has to pay for that.

\section{Question 11}

Interviewer: Do you think auto companies have managed the issues of recall prop- 
erly? Is it an issue of non-disclosure, or an issue of turning a blind eye?

Interviewee: In the United Kingdom VOSA does not issue a recall, it ensures that the car company, the manufacturer issues a recall, and only gets involved if there is an issue of significant safety question. As I said earlier most new cars are subject to campaigns, without the buyer knowing. It is only when there is a serious issue that it is subject to publicity. Now I can't comment on what happened in North America, I really can't comment because I don't just know much about that, but there were similar recalls here in the U.K., I think it had to do with processes at the manufacturers at the time, and I think the manufacturers have recovered that situation. It's a very difficult thing for manufacturers, it's a very fine line because of the nature of publicity that happens, and so most manufacturers will try to fix the defects without a publicity campaign.

\section{Question 12}

Interviewer: How can you describe the role of the media, in handling issues of recall? Over the Atlantic one or two people will complain that the way recalls are managed in Europe is different from how recalls are managed in America?

Interviewee: The whole approval process in America is different from how it is handled in Europe. So in America for safety aspects the vehicles are self-certified by the manufacturer, but in Europe the vehicles are type approved by the certification agency. So it's a significant difference between Europe and North America, and you can't compare the two. So I think we have a pretty robust system here in the United Kingdom, where the approving authority checks the functionality of the system, while the manufacturer is responsible for the reliability. It is a very competitive process these days that if a manufacturer sells a product that is unreliable, the manufacturer will face a significant challenge.

\section{Question 13}

Interviewer: How will you describe regulatory agencies like your, how have you been able to monitor the automobile industry?

Interviewee: Standards are set by NHTSA and the manufacturer then manufacture to meet those standards. In America the manufacturers are responsible for self-certification, and make them far more open to legal challenges by lawyers. In America you have a very active product reliability system. In Europe there is only one body, and when they certify there in nowhere else to go.

\section{Question 14}

Interviewer: I was reading and came across the acronym IATF, what do they do?

Interviewee: The IATF was initially set up by six vehicle manufacturers which is now nine, to type approve the quality standards of the supply chain, and to ensure that all meet up to ISOTS 16949. The IATF accredits certification bodies to audit to 16949, and VCA is an accredit certification body. So VCA has a number of clients where which they audit their processes to 16949 , so it's a manufacturing system process that is being audited. It is not parts that are being audited. It's a process, the manufacturing 
process that is being audited.

\section{Question 15}

Interviewer: When you audit the process, I see it as an incomplete thing, because the process can just be within a system. It is like you do the design these days, everything is simulated, and it goes to the manufacturing shop floor. Presently these days the automobile companies have leased everything out to the suppliers, tier 1, 2 and 3, they only do the assembling.

Interviewee: Not everything. You take most manufacturers they will make their own engines, they will make their own pressings. They will do their own paint, and they will do their trim and final assembly. A vehicle is made up of about 20,000 parts. If you look at a normal trim and final assembly line, they will only be assembling say 500 parts, because the others are accumulation of major systems. So your tier 0, 1, 2 and 3 suppliers are doing a degree of sub assembly. It's that process that ISOTS 16949 is looking at. There is no physical measurement of components with ISOTS 16949. Now most manufacturers have a separate process called P-Part or Initial Sampling Inspection where they physically measure the parts. Most manufacturers will do that, as the parts are supplied in. It also depends on the manufacturer's view of the quality of the supplier, so if it is a very large tier $0,1,1$ or 3 supplier, manufacturers just take the parts JIT and fix in the vehicle, and will only get into measurement and metrology if there is a problem, because they assume the quality of the arts supplied is ok. The suppliers take responsibility of the parts supplied, and manufacturers will only check when there is a problem.

\section{Question 16}

Interviewer: You were speaking about JIT just now, actually I didn't have it as one of my questions, but as someone who has worked over time in the automobile industry, I will like to ask if JIT is not a problem in manufacturing?

Interviewee: JIT is a good idea.

\section{Question 17}

Interviewer: When you say, you think it's a good idea does it not put pressure on the suppliers?

Interviewee: It does. What every manufacturer wants is for the parts to be built to standard, be it the size and its attributes. Then you want to make sure you get your statistical process control attributes in the right format.

\section{Question 18}

Interviewer: Now when you do a vehicle recall, if you are avoiding the waste in the shop floor, you didn't have high inventory in the shop floor, you didn't have unnecessary motion in the shop floor, at the end of the day, you recall over 1,000,000 vehicles as a result of defects, and you want to effect changes to those parts, is it not still waste?

Interviewee: It is waste. It is big waste; any cost of rectification is big waste. So what the manufacturers have to do is to learn why, when they have created a product, it still 
comes of defective. If you look at modern automobile companies, they are working now to cut down to parts per million the number of defects. If you look at your $1,000,000$ vehicles been recalled, there will only be a handful of those vehicles that will be registered with defect. Out of the 1,000,000 vehicles about 950,000 of them may have no defect, but the manufacturer has to replace all the components in the entire 1,000,000.

Interview with a Professor of International Business Strategy and Economics at XXXXXXXX University

This interview was conducted on the $19 / 08 / 2013$, by the researcher. The professor featured prominently in the BBC Two video "The Recall"; this necessitated the researcher meeting with him for a short interview about the Toyota strategy and its issues with recall.

\section{Question 1}

Interviewer: Thank you very much sir (Researcher introduces himself). After looking at the BBC 2 video, and seeing your discussion in it, I felt it will be good to get one or two information from you.

Professor: That's ok. Go ahead.

\section{Question 2}

Interviewer: Toyota's decided to grow its market share, sometime in 2002/2003 by $15 \%$, what were the consequences?

Professor: No, they actually decided to grow their output by $50 \%$, to arrive at a market share of about $15 \%$ in the world as a whole. Previously they were particularly focused on quality, quality, but now it became growth, and I think it was a fundamental change in their strategy. What it meant in practical term was that they built a lot of plants around the world, too many plant, in that they now carried to many capacity, they were carrying a lot of cost, and it meant that they had to look for ways to cut cost. That meant a big pressure in terms of cutting the cost, of parts, components, where they went for components was no longer their traditional suppliers. It also meant that one component was used for quite a number of models.

I think they basically went for growth, they themselves later admitted that during the congressional hearing.

\section{Question 3}

Interviewer: In issues of recalls, in your own view has Toyota handled it properly?

Professor: No, I think they acted too slowly. There were feedbacks coming from consumers in the United States, and I think they were not really acting on that, in their own view there wasn't a problem and part of the issue there was about the structure of the company. It's a very top down Japanese company, with headquarters in Japan and decisions were made in Japan. Sales and manufacturing in the U.S. were both reporting back to Japan, and the decisions were taken in Japan, they were way too slow. What they have actually done since the crisis is that they have changed their structure. 


\section{Question 4}

Interviewer: The Toyota Production System which metamorphosed into what is called Lean today and it's specifically a technique to eradicate all forms of waste, JIT is part of it, the supplier gets the parts or components to the manufacturer at the required quantity and time. Is Toyota still practicing the Toyota Way, with the numerous recalls, and maintenance works been done after recalls?

Professor: Yeah. Am not an expert on Lean systems; but I think it's still a waste. I know that the Toyota Way and the TPS is all about eliminating waste and ensuring proper quality. I will say they made huge mistakes, something went bad about their cars, and it impacted on their cost.

Their cost for fixing problems in America ran into hundreds of billions of dollars, which is just fixing it. Added to it is the fact that they had to cut back cost and win back its market share. This issue of recalls also led to their share price dropping, to a third of its value.

\section{Question 5}

Interviewer: Why is it that Toyota refuses to take responsibility when defects are found, even when it is clear that they work hand in hand with their suppliers. How can the suppliers also improve on the quality of their products?

Professor: Well am not really clear on whether it was a component failure or design failure. I think the president of Toyota put it in a more subtle way to the U.S. Congress, stating that they have failed; but, I don't know what the failure was.

I know they have had a long time committed relationship with their suppliers; but when they opened up to growth, they went looking for lower grade suppliers outside of Japan. That may yet again be part of the issue, they were looking for lower prices, and not necessarily the quality of the part supplied, possibly.

Submit or recommend next manuscript to SCIRP and we will provide best service for you:

Accepting pre-submission inquiries through Email, Facebook, LinkedIn, Twitter, etc.

A wide selection of journals (inclusive of 9 subjects, more than 200 journals)

Providing 24-hour high-quality service

User-friendly online submission system

Fair and swift peer-review system

Efficient typesetting and proofreading procedure

Display of the result of downloads and visits, as well as the number of cited articles

Maximum dissemination of your research work

Submit your manuscript at: http://papersubmission.scirp.org/

Or contact jtts@scirp.org 